\title{
Association of Hashimoto Thyroiditis (HT) with Papillary Thyroid Cancer (PTC)
}

\author{
Entela Puca ${ }^{1}$, Kadir Burak Koza ${ }^{2}$, Agron Ylli ${ }^{3}$ \\ ${ }^{1}$ Service of Endocrinology, American Hospital, Tirana, Albania \\ ${ }^{2}$ Service of Surgery, American Hospital, Tirana, Albania
}

${ }^{3}$ Department of Endocrinology, University Hospital Center, Tirana, Albania

\begin{abstract}
Introduction: Hashimoto thyroiditis (HT) is the most common autoimmune disease of thyroid gland. It characterized by a gradual autoimmune destruction of thyroid parenchyma with consequently thyroid failure with occasionally thyroid goiter. It's more prevalent in females than males. The same is for papillary thyroid cancer (PTC) is the most prevalent form of thyroid cancer and is more prevalent in females than males. Association between HT and PTC is controversial and still an open debate. So we undertookthis study to determine the association between HT and PTC. Material and Methods: In a retro and prospective study we analyzed the date of 155 patients 128 (82.5\%) females and 27 (17.5\%) males who underwent total or near total thyroidectomy for any thyroid pathology from April 2011 until April 2016. Results: HT was found in 30 (19, 3\%) of the 155 patients, (27 females and 3 males). Papillary thyroid cancer was found in 70 (46, 4\%) of 155 patients, (60 female or 85, 7\% and 10 males or 14,3\%). Co association of PTC with HT was found in 17 (10, 9\%) of 155 patients,(15 females, 88, 3\% and 2 males 11, 7\%). Among the group of PTC 70 patients, the prevalence of HT was 24, $2 \%$ (17 patients), 15 females (88, 2\%) and 2 males (11,3\%), which was higher than the prevalence of HT in other patients without PTC (15,3\%), 12 females (92, 3\%) and one male (7, 7\%). Among of 30 patients with HT prevalence of PTC was 56, $6 \%$ (17 patients), which was higher than the prevalence of PTC in other patients without HT (42,4\%). However, there was no statistically significant difference ( $\chi 2=1.98, d f=1, p=0.15)$ between the presence of PTC in specimens with HT and the presence of PTC in other HT negative patients. There was no significant difference in age (Chi-Sq $0,0005, p=0,18$ ), at the time of diagnosis between PTC patients with and without $\mathrm{HT}$. there is a significant difference in tumor size between patients with or without $\mathrm{HT}(\mathrm{Chi}-\mathrm{Sq} 7,800, p=0,02)$. Prevalence of microcarcinoma was higher in patient with HT than non HT 28,3\%, versus $7 \%$ with a statistically significant difference (Chi-Sq =7,30 df=1, p=0.006). HT was more often observed in multifocal PTCs than in single PTCs (P=0, 07). Conclusion: In conclusion, the existing data provide inconsistent evidence favoring a causal relationship between HT and PTC. For the moment there is no valid criteria to identify those patients with HT which are at high risk for developing PTC. Careful observation and close follow-up of HT patients with nodular structure is recommended
\end{abstract}

Keywords: Hashimoto thyroiditis, papillary thyroid cancer, autoimmune disease

\section{Introduction}

Hashimoto thyroiditis (HT) is the most common autoimmune disease of thyroid gland. It's characterized by a gradual autoimmune destruction of thyroid parenchyma with consequently thyroid failure with occasionally thyroid goiter (1). For the first time it's been described by Hakaru Hashimoto a Japanese surgeon who worked in Berlin, Germany(2,3).The annual incidence of HT is estimated to be around 0,3-1,5case for 1000 individuals and it more prevalent in females than in males with a ratio going from 5 until 20:1 (4,5).The same is for papillary thyroid cancer (PTC). Itis the most prevalent form of thyroid cancer around $70-80 \%$ of all thyroid cancer.It's more prevalent in females than males(6).Correlation between HT and PTC is first described from Dailey et al in 1955 (7).From that time and now it's still an open debate and the dates are still controversial. Some study report a positive correlation between 11 until $36 \%$ (8 -11) and other didn't observed any correlation (12-14).

Considering the high prevalence of these two diseases of thyroid gland and ongoing debate that still is controversial we decided to perform this study to determine the association of Hashimoto's thyroiditis with PTC.

\section{Material and Methods}

This is a retrospective study in which we analyzed the clinical and histopathologicaldata of 155 patientsfrom January 2014 until December 2015. From the total of 155 patients, females were 128 (82,5\%) andmales 27 (10,9\% ); mean age was $44,9 \pm 14,09$ (range16-73) years. The inclusion criteria were patient over 16 years old who underwent total or near total thyroidectomy for any thyroid pathology. Indication for thyroidectomy wasfine needle aspiration (FNA) results for malignancy or suspicious for follicular malignancy (FNA results based on the Bethesda 2009 classification from I to VI), retrosternal multinodular goiter, fear for malignancy, or also benign FNA cytology but with increased size of the nodules or with ultrasound features suspicious for thyroid cancer (TC).The diagnosis and classification of TC is done according to the WHO and TNM system.A diagnosis of HT wasconfirmed by histopathology in the presence oflymphocytic infiltrations in thethyroid parenchyma and with formation of reactioncenters and lymphoid nodules. Peri-tumoral lymphocytic infiltrations were not considered as HT. General characteristic of the patients were included age, gender and also histopathology report. Pathological parameters were also included nodule size, multifocality.

Statistical analyzes: The results are expressed as the means \pm standard deviation (SD).The statistical analysis was 


\section{International Journal of Science and Research (IJSR) \\ ISSN (Online): 2319-7064 \\ Index Copernicus Value (2013): 6.14 | Impact Factor (2014): 5.611}

performed using the $\chi^{2}$-test for the relationships between the variables and PTC were calculated using binary logistic regression. A p-value of less than 0.05 was considered statistically significant.

\section{Results}

General characteristic of the patients. The indication for thyroid surgery and also the prevalence of histopathologicalof the entire patient who performed thyroidectomy are listed at table 1and 2.

Table 1: Reason for total or near total thyroidectomy

\begin{tabular}{|c|c|}
\hline Reason for thyroidectomy & $\begin{array}{c}\text { Number of patients } \\
\text { (\%) N =155 }\end{array}$ \\
\hline $\begin{array}{c}\text { FNA positive or suspicious for malignancy } \\
\text { from TIR3 to TIR 6 }\end{array}$ & $63(40.6 \%)$ \\
\hline Toxic and Non-toxic MultinodularGoiter & $68(44 \%)$ \\
\hline Graves disease & $4(2,5 \%)$ \\
\hline Large or obstructive MultinodularGoiter & $20(12,9)$ \\
\hline
\end{tabular}

Table 2: Histopathology dates for all patients

\begin{tabular}{|c|c|c|}
\hline Histopathology diagnoses & $\begin{array}{c}\text { Nr of patients } \\
\text { and }(\%)\end{array}$ & $\begin{array}{c}\text { Ratio Female/ } \\
\text { Male, } 128 / 27\end{array}$ \\
\hline PTC without HT & $53(34,1)$ & $45 / 8$ \\
\hline FTC & $2(1,3)$ & $2 / 0$ \\
\hline HT & $30(19,3)$ & $27 / 3$ \\
\hline PTC with HT & $17(10,9)$ & $15 / 2$ \\
\hline Others Medullary thyroid cancer & $1(0,6)$ & $0 / 1$ \\
\hline Anaplasic thyroid cancer & $1(0,6)$ & $0 / 1$ \\
\hline $\begin{array}{c}\text { Benign pathology (nodular goiter, } \\
\text { hyperplasic nodules, adenoma) }\end{array}$ & $81(48,3)$ & $67 / 14$ \\
\hline
\end{tabular}

The association of PTC with HT is shown in table 3. HT wasfound in $30(19,3 \%)$ of the 155 patients, (27 females or $90 \%$ and 3 males $10 \%)$. PTC was found in $70(46,4 \%)$ of 155patients, (60 females85,7\%with 10 males 14,3\%). Co association of PTC with HT was found in 17 (10,9\%) of 155 patients,(15 females,88,3\%and 2males 11,7\%). Among the group of PTC70 patients, the prevalence of HT was $24,2 \%$ (17 patients), 15 females (88,2\%) and 2 males (11,3\%), which was higher than the prevalence of HT in other patients without PTC (15,3\%), 12 females (92,3\%) and one male (7,7\%). Among the 30 patients with HT prevalence of PTC was 56,6 \% (17patients), which was higher than the prevalence of PTC in other patients without HT $(42,4 \%)$. However, there was no statistically significant difference $(\chi 2$ $=1.98, \mathrm{df}=1, \mathrm{p}=0.15$ ) between the presence of PTC in specimens with HT and the presence of PTC in other HT negative patients.. There was no significant difference in age (Chi-Sq 0, 0005, p=0,18), at the time of diagnosis between PTC patients with and without HT. There is a significant difference in tumor size between patients with or without HT (Chi-Sq 7,800; p=0,02) see table 3. Prevalence of microcarcinoma was higher in patient with HT than non HT $28,3 \%$, versus $7 \%$ with a statistically significant difference (Chi-Sq =7,30 df=1, p=0.006).

Table 3: Association between HT and PTC in 155 patients

\begin{tabular}{|c|c|c|c|}
\hline $\begin{array}{c}\text { Histopathology } \\
\text { diagnosis }\end{array}$ & HT present & $\begin{array}{c}\text { HT non } \\
\text { present }\end{array}$ & total \\
\hline PTC present & 17 & 53 & 70 \\
\hline PTC absent & 13 & 72 & 85 \\
\hline Total & 30 & 155 & 155 \\
\hline
\end{tabular}

Table 4: Clinico-pathologic characteristics of PTC patients with or without HT

\begin{tabular}{|c|c|c|c|c|}
\hline \multicolumn{2}{|c|}{ Variables } & PTC total & $\begin{array}{l}\text { Hashimoto } \\
\text { Thyroiditis } \\
\text { (Yes) N } 17\end{array}$ & $\begin{array}{l}\text { Hashimoto } \\
\text { Thyroiditis } \\
\text { (No) N } 53\end{array}$ \\
\hline \multicolumn{2}{|c|}{$\begin{array}{l}\text { Age(years) mean } \pm \text { SD at } \\
\text { the moment of diagnoses }\end{array}$} & $43,0 \pm 15,03$ & $43,11 \pm 13$ & $42,4 \pm 15,9$ \\
\hline \multicolumn{2}{|c|}{ Gender female/male } & $60 / 10$ & $15 / 2$ & $43 / 10$ \\
\hline \multirow{3}{*}{ Tumor size } & $\geq 10 \mathrm{~mm}$ & & 11 & 15 \\
\hline & $11-20 \mathrm{~mm}$ & & 3 & 20 \\
\hline & $>20 \mathrm{~mm}$ & & 3 & 18 \\
\hline \multicolumn{2}{|c|}{ multifocality } & 32 & 11 & 21 \\
\hline \multicolumn{2}{|c|}{ Single focus } & 38 & 6 & 32 \\
\hline
\end{tabular}

The majority of the patient with PTC were females(60 versus 10 males); there was no statistically significant gender difference between PTC patients with and without HT $(\chi 2=1,98: \mathrm{df}=1)$. HT in PTCs was observed in 15 of 60 (25\%) females' patients and in 2 of 10 (20\%) male patients. On the basis of this finding, there was a high association of HT in PTCs with females but not statistically significant $\mathrm{P}=$ 0.73 see table 4 . HT was present in $6(15,7 \%)$ of 39 single PTCs and in 11 (33,3 \%) of 32 multifocal PTCs. HT was more often observed in multifocal PTCs than in single PTCs $(\mathrm{p}=0,07)$.

\section{Discussion}

The association between PTC and HT has been widely debated andit's still so in the literature. Our findings showed a low rate of association between PTC and HT around $10,9 \%$ and no statistically significant relationship between the presence of $\mathrm{HT}$ and the presence of PTC in histopathology material of 155 patients who underwent total or near total thyroidectomy. Several study gives strong correlation between PTC and HT but other failed to give any significant correlation between these two diseases $(7,9,15$ 18). In a Sicilian study of 282 patients who underwent thyroid surgery for any pathology, HT was detected in $24 \%$ of patients with PTC (17);Matesa-Anic et al did not find any statistically significant relationship between HT and PTC in FNA cytological from 10,508 patients; coexistence of HT and PTC was reported $0.4 \%$ of all patients undergoing FNAC. The differences between studies about the prevalence of coexistence of the HT and PTC may be explained by different prevalence of each disorders, patients selection (gender, age), it could be attributed to the indications for thyroidectomy, differences in the pathologic definitions and different diagnostic criteria for HT (someconfirmed the diagnoses with the presence of any thyroid antibodies and other by pathology. Several studies didn't have a control group so therefore, risk ratio could not be calculated. As expected HT was more prevalent in female than in males, (27 female and 3 males), because female express more thyroid autoimmunity disease then males (3), but we couldn't confirmed any statistical difference in age and gender between patients with PTC with or without HT (15). It can be related with the small number of males in our study. The presence of HT in our study on histopathology result was $19,3 \%$. In the study of Staii et al the prevalence of HT diagnosed by cytology was $13.4 \%$ (19). Prevalence of papillary thyroid microcarcinoma (PTMC) was higher in patient with HT than non HT 28,3\% versus $7 \%$ with a

\section{Volume 5 Issue 3, March 2016}




\section{International Journal of Science and Research (IJSR) \\ ISSN (Online): 2319-7064 \\ Index Copernicus Value (2013): 6.14 | Impact Factor (2014): 5.611}

statistically significant difference (Chi-Sq $=7,30 \mathrm{df}=1$, $\mathrm{p}=0.006$ ). In a study of Slijepcevic et al the prevalencence of PTMC was reported $16.3 \%$ (20). HT was more often observed in multifocal PTCs than in single PTCs $(p=0,07)$. Lee et al in a meta-analysis reported that HT was more often observed in multifocal PTCs than in single PTCs (ORZ1.467; 95\% CI 1.096-1.964; PZ0.010) (21).

In conclusion, the existing data provide inconsistent evidence favoring a causal relationship between HT and PTC. These was a retrospective study related with possible selection of bias so prospective studies involving a large number of patient will be need to elucidate the relationship between HT and PTC. For the moment there are no valid criteria to identify those patients with HT which are at high risk for developing PTC. Careful observation and close follow-up of HT patients with nodular structure is recommended.

\section{References}

[1] Lal G, Clark OH. Textbook of endocrine surgery. Philadelphia: Saunders; 2005. Chronic Thyroiditis; p. 38-40.

[2] Vanderpump MP, Tunbridge WM, French JM. The incidence of thyroid disorders in the community: a twenty-year follow-up of the Whickham Survey. ClinEndocrinol.1995;43:55-68.

[3] Mazakopakis E, Tzortzinis A, Dalieraki-Ott E, et al. Coexistence of Hashimoto's thyroiditis with papillary thyroid carcinoma. A retrospective study. Hormones (Athens). 2010;9:312-318.

[4] DaileyME, LindsayS, SkahenR." Relation of thyroid neoplasms to Hashimoto disease of the thyroid gland," Archives of Surgery.1955;70:291-297.

[5] Davies L, Welch HG. Increasing incidence of thyroid cancer in the United States, 1973-2002. JAMA. 2006;295:2164 -2167.

[6] JankovicB,LT, Jerome M. HershmanHashimoto's Thyroiditis and Papillary Thyroid Carcinoma: Is There a Correlation? J ClinEndocrinolMetab. 2013, 98(2):474 482.

[7] Dailey ME, Lindsay S, Skahen R. Relation of thyroid neoplasmsto Hashimoto's disease of the thyroid gland. Arch Surg1955;70: 291-297.

[8] Singh B, Shaha AR, Trivedi H, Carew JF, Poluri A, Shah JP. Coexistent Hashimoto's thyroiditis with papillary thyroid carcinoma: impact on presentation, management, and outcome. Surgery 999;126:10701076.

[9] Cipolla C, Sandonato L, Graceffa G, Fricano S, Torcivia A, Vieni S et al. Hashimoto thyroiditis coexistent with papillary thyroid carcinoma. Am. Surg. 2005;71:874-878.

[10] Rivero VP, Camacho GM, Garcia MM, Ruiz TG, Romero PG, Palomino GA et al. The incidence of thyroid carcinoma in Hashimoto's thyroiditis. Ourexperience and literature review. An Otorrinolaringol. Ibero. Am 2004;31:223-230.

[11] Okayasu I, Fujiwara M, Hara Y, Tanaka Y, Rose NR. Association of chronic lymphocytic thyroiditis and thyroid papillary carcinoma. A study of surgical cases among Japanese, and white and African Americans. Cancer 1995;76:2312-2318.

[12] Holm LE, Blomgren H, Lo"whagen T. Cancer risks in patients with chronic lymphocytic thyroiditis. N Engl J Med 1985;312:601-604.

[13] Rago T, Di Coscio G, Ugolini C, et al. Clinical features of thyroidautoimmunity are associated with thyroiditis on histology and arenot predictive of malignancy in 570 patients with indeterminate nodules on cytology who had a thyroidectomy. ClinEndocrinol(Oxf) 2007;67:363-369.

[14] Crile G Jr. Struma lymphomatosa and carcinoma of the thyroid.Surg Gynecol Obstet 1978;147:350-352.

[15] Kebebew E, Treseler PA, Ituarte PHG, Clark OH. Coexisting chronic lymphocytic thyroiditis and papillary thyroid cancer revisited. World J Surg2001;25:632-637.

[16] SchafflerA, Palitzsch KD, Seiffarth C, et al. Coexistent thyroiditis is associated with lower tumour stage in thyroid carcinoma. Eur J Clin Invest.1998;28:838-844.

[17] Costanzo M, Caruso LA, Testa R, MarzianiA, Cannizzaro MA. Hashimoto thyroiditis. Possible cause or consequence of a malignant thyroid tumor. Ann ItalChir2006;77:469-471.

[18] MatesaAD, Matesa N, Dabelic N, Kusic Z. Coexistence of papillary carcinoma and Hashimoto's thyroiditis. ActaClin Croat.2009;48:9-12.

[19] Staii A, MirochaS, KotevaK, GlinbergS, JaumeJC. Hashimoto thyroiditis is more frequent than expected when diagnosed by cytology which uncovers a preclinical state. Thyroid Research. 2010;3:11-15.

[20]Slijepcevic N, Sipetic S,DiklicA,Paunov I.Retrospective evaluation of the incidental finding of 403 papillary thyroid microcarcinomas in 2466 patients undergoing thyroid surgery for presumed benign thyroid disease. BMC Cancer. 2015;15:330-335.

[21] Lee JH, Kim Y, Choi JW, Kim Ys.The association between papillary thyroid carcinoma and histologically proven Hashimotos thyroiditis:a meta-analysis.Eur J Endocrinol. 2013 Feb $15 ; 168(3): 343-349$. 